\title{
Aesthetic implant: A new era of aesthetic dentistry
}

\author{
Md. Mujibur Rahman Howlader, Tahmina Tamanna, Md. Abdul Hannan Sheikh, Rozina Akter, \\ Tohfa-A-Zannat, Siddiqullah, Md. Shamsul Alam and Md. Ali Asgor Moral
}

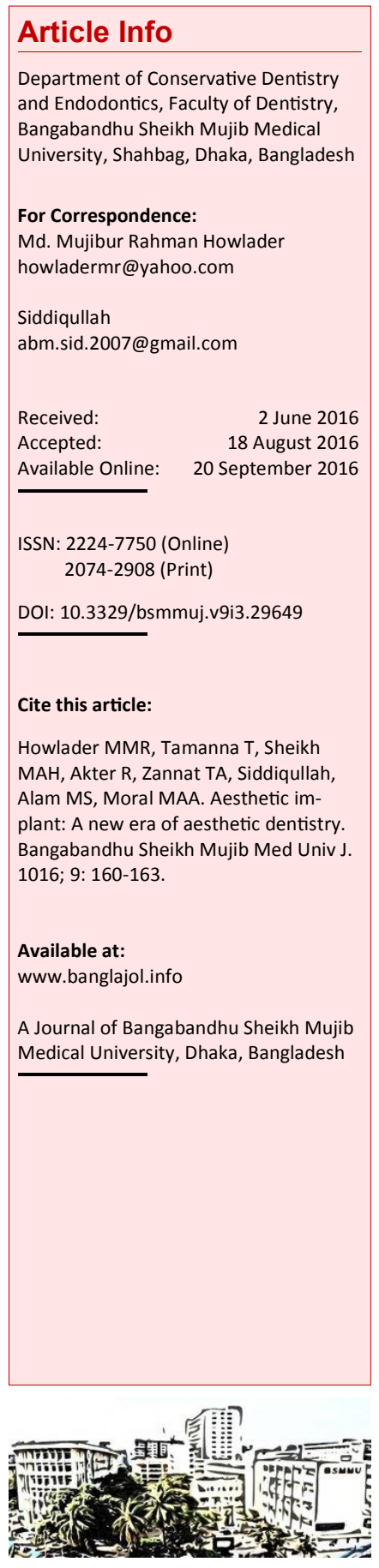

\section{Abstract}

The dental implant is used to replace the natural tooth system. It requires comprehensive preoperative planning and precise surgical execution. In this case report, a 45 year old male presented with missing upper left maxillary central incisor which was extracted 5 months back. He had discomfort during function and unwillingness to smile. He wanted to replace that edentulous area. The treatment options for replacing the missing tooth were discussed with the patient. Finally, with patient's consent the decision was made to replace that edentulous area with an implant supported porcelain fused to metal prosthesis in an esthetic manner. Recall visits exhibited patient's high-level confidence of smile with optimum satisfaction and successful aesthetic outcome.

\section{Introduction}

To create flawless esthetic anterior implant replacements for teeth take time, persistence, clinical acumen, a favorable tissue biotype and plain luck. The use of advanced surgical technique and implant design feature in the esthetic zone are the successful and predictable option for tooth replacement.1-5 However, there are some obstructions in the use of dental implants..-9 Smaller edentulous intertooth spaces, convergent roots, reduced transverse or vertical dimension of the residual ridge and close proximity of root trunks need to use other options to replace the natural tooth system. This alternative is usually prosthesis either fixed resin-bonded or removable.

Placing a single implant in the anterior maxilla is a multifactorial process that requires attention to detail. When placing implants in this esthetic area, maintaining the bone architecture of the implant site and the accompanying gingival contours is vital.10,11 Kois described five diagnostic keys (relative tooth position, periodontium form, periodontium biotype, tooth shape, and position of the osseous crest) to help the clinician determine the predictability of peri-implant esthetics. 12 Optimal support and stability of the peri-implant soft and hard tissue depend on the correct 3dimensional placement of the implant.

Buser et al suggested the following guidelines for implant placement: first, the mesiodistal distance between the adjacent teeth and the implant should not be less than 1 to $1.5 \mathrm{~mm}$. In addition, the facial implant shoulder point of emergence of the adjacent teeth for the proper emergence profile of the implant crown, and the top of the implant shoulder should be placed approximately $1 \mathrm{~mm}$ apical to the cement-enamel junction of the facial surface of the contralateral tooth with no recession. $\underline{13}$

The final location of the facial gingival margin and the preservation of the interdental papilla help to determine the esthetic outcome of an anterior implant. The buccal bone crest is comprised of bundle bone, which resorbs more readily after tooth extraction than palatal bone, which has a cortical bone plate.11 A $25 \%$ bone width reduction of the maxillary anterior ridge can occur within the first year of loss of a tooth. 10 To minimize the amount of facial bone resorption after implant placement, a labial bone thickness of 1.8 to $2 \mathrm{~mm}$ is desired. $\underline{14}$ Small -diameter implants (width diameter: 1.8-5 mm, length: 8-16 $\mathrm{mm}$ ) are available. These are used in the immediate stabilization of bone augmented ridges to esthetic tooth replacement in the esthetic zone.

The following case report demonstrates the esthetic concerns involved in missing maxillary incisor with a minimally invasive surgical placement approach.

\section{Case Report}

A 45 year old male presented to the Depart- 


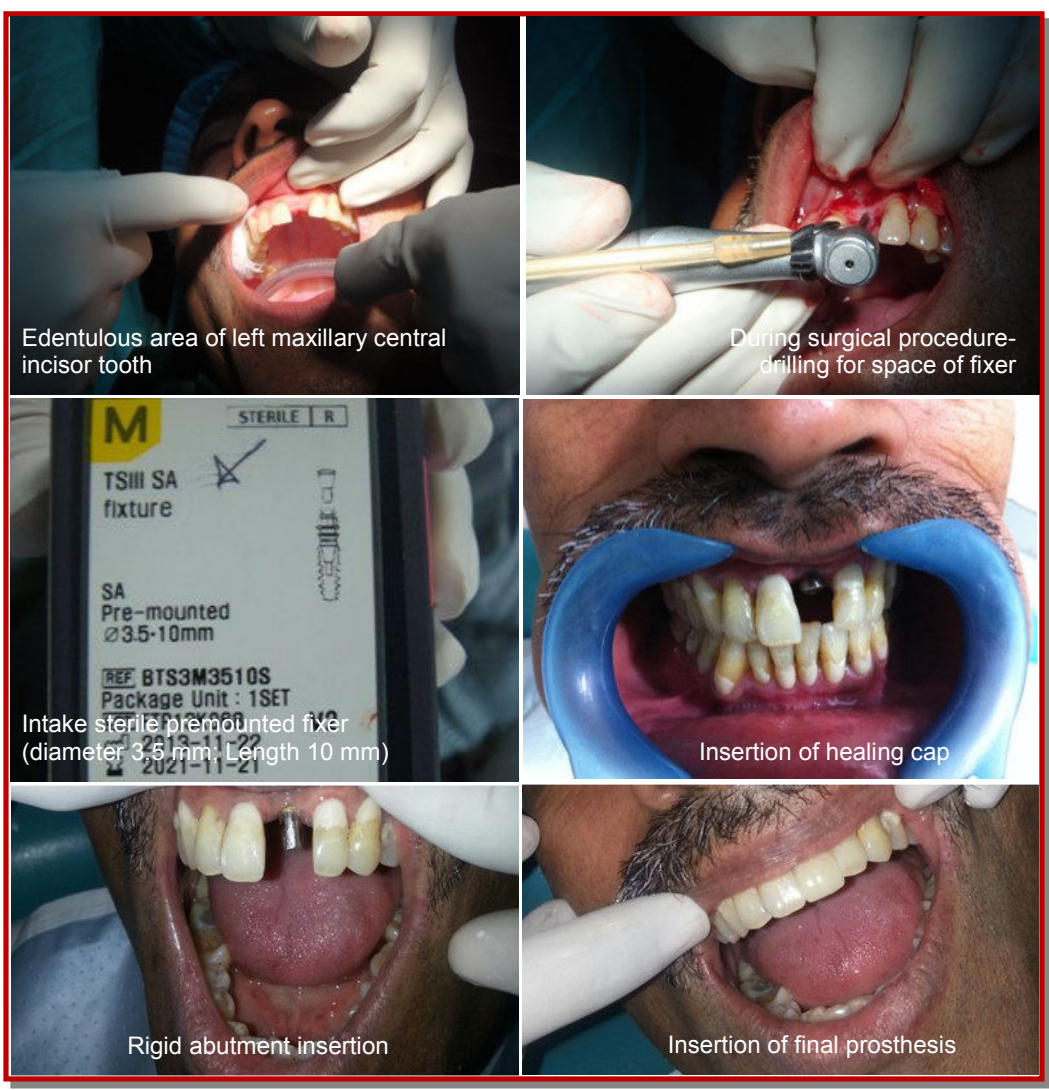

Figure 1: Photographs of the patient

ment of Conservative Dentistry and Endodontics of Bangandhu Sheikh Mujib Medical University for restorative consultation regarding his missing upper left maxillary central incisor which was extracted five months back. His complaint was a lack of comfort during function and unwillingness to smile. The edentulous space measured $6.0 \mathrm{~mm}$ in between 11 and 22. The preoperative X-ray of the periapical region showed clear intertooth space between the roots of teeth Nos. 11 and 22. The treatment options for replacing the missing tooth were discussed with the patient, including a removable partial denture, a fixed partial denture, and an implant crown. Then the patient agreed to replace that edentulous area with an implant supported porcelain fused to metal prosthesis.

After preliminary observation of soft and hard

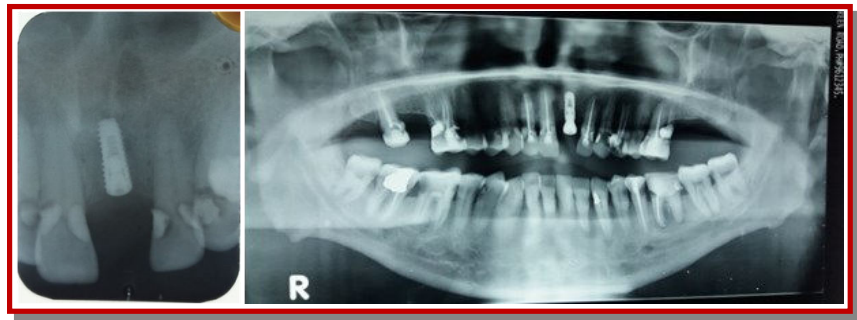

Figure 2: Radiographic view of post insertion of fixer (left); after implant surgeryOPG (after 3 months) (right) tissue, proper mouth preparation was carried out and the patient was premedicated with antibiotic, NSAID and an oral antibiotic rinse. Local infiltration of the soft tissues in the maxilla was completed at sites Nos. 12 to 23 with lidocaine with 1:100,000 epinephrine followed by 1:50,000 for surgical hemostasis. Full thickness flap was raised. The surgical guide was placed into the edentulous site and a marking made in the gingival osseous crest with a round \#6 bur in the implant handpiece. This registered the planned implant location in the osseous gingival crest. The creation of the esthetic soft tissue emergence profile in the gingival and osseous tissue was achieved with a football shaped medium-coarse diamond. This emergence profile was then made to sculpt the interdental soft tissue contours, with the facial emergence profile that was necessary to achieve balance and symmetry with the adjacent teeth and the contralateral tooth in the anterior segment (Figure 1). When this was accomplished, the osteotomy site was cored to $2.5 \times 10$ $\mathrm{mm}$ in size, followed by increasing the diameter of the site to $3 \mathrm{~mm}$ with the subsequent spade drill. One-piece implant $(3.5 \times 10 \mathrm{~mm})$ was seated into the osteotomy site using more instrumentation. Care was given to the placement parameters. For every full rotation of the implant collar, $1.25 \mathrm{~mm}$ of the depth of the threads was engaged apically into the osseous crest. It was important because the facial aspect of the collar of the abutment portion of the implant must be to the facial since it was more crystally placed in relation to the palatal margin of the abutment aspect of the implant. This allowed for a more sculpted facial emergence profile. The implant was confirmed to be in the appropriate position. The space present between the adjacent roots of the natural teeth and the implant was confirmed by immediate postoperative periapical $\mathrm{X}$ ray (Figure 2). Finally, the flap was sutured and the patient was asked for a post-operative follow-up.

After 12 weeks, the second surgical phase was carried out involved the placement of abutment. Under local anesthesia, abutment was installed. The abutment was prepared to provide ideal alignment and emergence profile of the crown. The tissues were allowed to mature 4 weeks and the patient returned for impression appointment.

The final porcelain fused to metal prosthesis was fabricated to optimize the esthetics. The final crown was tried in and evaluated for fit, function, and esthetics. Once the patient accepted the esthetics of the prosthesis, it was cemented and the patient was advised to come for regular follow-up (Figure 3).

\section{Discussion}

Tissue health and implant survival were the main concern even in the early years of modern implantology. During the last decade, there was an 


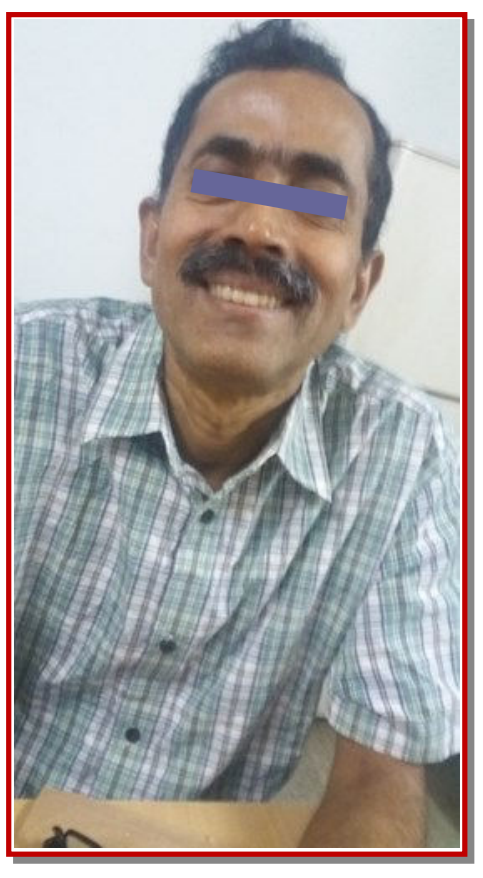

Figure 3: Smile makeover increasing appreciation that esthetics is just as important to the success of the final restoration of health. A 5-year multicenter study shows an implant success rate of $96 \%$ for single-tooth replacements in the anterior maxilla. However, the esthetic failure rate of $9 \%$ was reported. 15 This indicates the importance of esthetics for the success of implant and patient satisfaction.

The failing tooth should be evaluated first in relation to the adjacent dentition in the apico-coronal, mesiodistal, and faciopalatal planes. $\underline{12}$ In this case, maxillary left central incisor had an unfavorable gingival margin, positioned $1 \mathrm{~mm}$ more apical than the adjacent dentition.

The gingival biotype must be assessed. Such assessment will partly determine the risk for postsurgical recession. $\frac{12,16}{16}$ Gingival biotype of thin and highly scalloped type is less resistant to trauma from surgical or restorative procedures. Consequently, it is more prone to recession in comparison with a thick, flat gingival biotype. In this case, assessment of gingival biotype was quite satisfactory.

The bone quality and quantity must be assessed carefully as because the supporting bone has an influence on the establishment of overlying soft tissue. 17,18 The vertical bone height in the interproximal sites, as well as the horizontal thickness and vertical height of the buccal bone wall in the edentulous site are important determinants of esthetic success.18-22 The bone crest should be within a physiological distance of 2 to $3 \mathrm{~mm}$ of the cemento -enamel junction or, when the recession is present, 2 to $3 \mathrm{~mm}$ of the buccal gingival margin. Fortunately, this case was within the measured limit.

The surgical approach must be carefully planned and executed. The guidelines for implant placement and restoration in the esthetic zone were proposed.23 The surgeon should follow a) conservative flap design, b) evaluating the existing bone and soft tissue, c) time of placement correctly, d) visualize the three-dimensional position of the implant considers healing time before implant loading, e) considering the determinants of emergence profile, and f) select a proper abutment and final restoration design.

The implant should ideally be placed so that the abutment resembles the preparation of a natural tooth. In screw-retained prostheses, poor angulation can alter screw placement. This has a significant effect on esthetics. 24 Implants positioned with too much angulation either toward the palatal or the buccal often compromise esthetics. It may also impact home care. 25 It is usually accepted that the angulation of implant should mimic the angulation of adjacent teeth if the teeth are in reasonably good alignment. Most of the cases the implant includes a provision for some type of angled or custom abutments to compensate for situations where ideal alignment may not be possible. Surgical guides can help provide the right angulation, as this may be difficult to visualize at the time of surgery. In the maxillary anterior regions, a subtle palatal angulation is sometimes recommended to increase labial soft tissue bulk and to avoid the problems with thin buccal walls. $\underline{23}$

Upon completion of the case, a natural appearing soft tissue emergence profile was obtained at the implant site along with the balance and symmetry of the adjacent restorations.

\section{Conclusion}

The implant could be an effective, safe and alternative method to that of conventional prosthesis work.

\section{References}

1. Kan JY, Rungcharassaeng K. Immediate placement and provisionalization of maxillary anterior single implants: A surgical and prosthodontic rationale. Pract Periodontics Aesthet Dent. 2000; 12: 817-24.

2. Saadoun AP. Immediate implant placement and temporization in extraction and healing sites. Compend Contin Educ Dent. 2002; 23: 309-12.

3. Petrungaro PS. Immediate implant placement and provisionalization in edentulous, extraction, and sinus grafted sites. Compend Contin Educ Dent. 2003; 24: 95-100.

4. Petrungaro PS. Immediate restoration of implants utilizing a flapless approach to preserve interdental tissue contours. Pract Proced Aesthet Dent. 2005; 17: $151-58$.

5. Wohrle PS. Single-tooth replacement in the aesthetic zone with immediate provisionalization: Fourteen consecutive case reports. Pract Periodontics Aesthet Dent. 1998; 10: 1107-14.

6. Hansson O. Clinical results with resin-bonded prostheses and an adhesive cement. Quintessence Int. 1994; 25: 125-32.

7. Shugars DA, Bader JD,White BA, et al. Survival rates of teeth adjacent to treated and untreated posterior bounded edentulous spaces. J Am Dent Assoc. 1998; 129: 1089-95.

8. Wallace SS. Significance of the 'biologic width' with respect to root-form implants. Dent Implantol Update. 1994; 5: 25-29.

9. Misch CE. Early bone loss etiology and its effect on treatment planning. Dent Today. 1996; 15: 44-51. 
10. Misch CD. Misch C. Contemporary implant dentistry. 3rd ed. USA, Mosby Elsevier, 2008.

11. De Rouck T, Collys K, Cosyn J. Single-tooth replacement in the anterior maxilla by means of immediate implantation and provisionalization: A review. Int J Oral Maxillofac Implants. 2008; 23: 897 $-904$.

12. Kois JC. Predictable single-tooth peri-implant esthetics: Five diagnostic keys. Comp Contin Educ Dent. 2001; 25: 895-96.

13. Buser D, Martin W, Belser UC. Optimizing esthetics for implant restorations in the anterior maxilla: Anatomic and surgical considerations. Int J Oral Maxillofac Implants. 2004; 19(Suppl): 43-61.

14. Spray JR, Black CG, Morris HF, Ochl S. The influence of bone thickness on facial marginal bone response: Stage 1 placement through stage 2 uncovering. Ann Periodontol. 2000; 5: 119-28.

15. Henry PJ, Laney WR, Jemt T, et al. Osseointegrated implants for single-tooth replacement: A prospective 5-year multicenter study. Int J Oral Maxillofac Implants. 1996; 11: 450-55.

16. Jansen CE, Weisgold A. Presurgical treatment planning for the anterior single-tooth implant restoration. Compend Contin Educ Dent. 1995; 16: 746.

17. Saadoun AP, Le Gall MG. Periodontal implications in implant treatment planning for aesthetic results. Pract Periodontics Aesthet Dent. 1998; 10: 655-64.

18. Garber DA, Belser UC. Restoration-driven implant placement with restoration-generated site development. Compend Contin Educ Dent. 1995; 16: 796, 798-802, 804

19. Belser U, Buser D, Higginbottom F. Consensus statements and recommended clinical procedures regarding esthetics in implant dentistry. Int J Oral Maxillofac Implants. 2004; 19(Suppl): 73-74.

20. Kan JY, Rungcharassaeng K, Umezu K, et al. Dimensions of peri-implant mucosa: An evaluation of maxillary anterior single implants in humans. J Periodontol. 2003; 74: 557-62.

21. Anson D. Maxillary anterior esthetic extractions with delayed single-stage implant placement. Compend Contin Educ Dent. 2002; 23: 829-30, 833 826,838 .

22. Tarnow D, Elian N, Fletcher $\mathrm{P}$, et al. Vertical distance from the crest of bone to the height of the interproximal papilla between adjacent implants. J Periodontol. 2003; 74: 1785-88.

23. Tischler M. Dental implants in the esthetic zone. Considerations for form and function. NY State Dent J. 2004; 70: 22-26.

24. Sullivan DY, Sherwood RL. Considerations for successful single tooth implant restorations. J Esthet Dent. 1993; 5: 118-24.

25. Davarpanah M, Martinez H, Celletti R, et al. Threestage approach to aesthetic implant restoration: emergence profile concept. Pract Proced Aesthet Dent. 2001; 13: 761-77. 